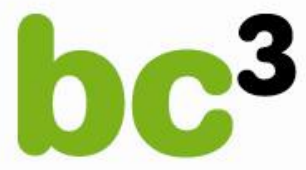

BASQUE CENTRE

FOR CLIMATE CHANGE

Klima Aldaketa Ikergai

\title{
The Equivalency Principle for Discounting the Value of Natural Assets: An Application to an Investment Project in the Basque Coast
}

Aline Chiabai, Ibon Galarraga, Anil Markandya and Unai Pascual

October 2011

BC3 WORKING PAPER SERIES

2011-10 
The Basque Centre for Climate Change (BC3) is a Research Centre based in the Basque Country, which aims at contributing to long-term research on the causes and consequences of Climate Change in order to foster the creation of knowledge in this multidisciplinary science.

The BC3 promotes a highly-qualified team of researchers with the primary objective of achieving excellence in research, training and dissemination. The Scientific Plan of BC3 is led by the Scientific Director, Prof. Anil Markandya.

The core research avenues are:

- Adaptation to and the impacts of climate change

- Measures to mitigate the amount of climate change experienced

- International Dimensions of Climate Policy

- Developing and supporting research that informs climate policy in the Basque Country

See www.bc3research.org for further details.

The BC3 Working Paper Series is available on the internet at

http://www.bc3research.org/lits_publications.html

Enquiries (Regarding the BC3 Working Paper Series):

Roger Fouquet

Email: roger.fouquet@bc3research.org

www.bc3research.org

The opinions expressed in this working paper do not necessarily reflect the position of Basque Centre for Climate Change (BC3) as a whole.

Note: If printed, please remember to print on both sides. Also, perhaps try two pages on one side. 


\title{
The equivalency principle for discounting the value of natural assets: An application to an investment project in the Basque Coast
}

\author{
Aline Chiabai ${ }^{1}$, Ibon Galarraga ${ }^{2}$, Anil Markandya $^{3}$, Unai Pascual ${ }^{4}$
}

\begin{abstract}
Making decisions about optimal investments in green infrastructure necessitates setting social discount rates. This paper suggests a practical way for determining the discount rate for projects or programmes in which one of the options is to maintain or improve land in its natural state. We propose an "equivalency principle" to derive a simple rule that sets the discount rate. The rule is based on the premise that the long term value of a naturally preserved land track ought to be at least the same as the value of an identical land track in the vicinity to which permission has been granted for development. We illustrate this principle with various case studies and we apply it to a contentious investment project in the Basque Country associated with the regeneration of a large scale harbour in the province of Gipuzkoa (North of Spain) that involves reclaiming natural land that has important ecological value, including for the conservation of a marine ecosystem.
\end{abstract}

Keywords: Economic valuation, discounting, equivalency principle, Basque Country.

\footnotetext{
${ }^{1}$ Basque Centre for Climate Change (BC3), Alameda Urquijo 4, 4º $-1^{\mathrm{a}}$. 48008 Bilbao (Spain). Tel: +34944014690. Fax: +34 94405 4787. Web: www.bc3research.iorg. Corresponding author: aline.chiabai@ bc3research.org. 2 BC3.

3 BC3 and IKERBASQUE, Basque Foundation for Science. Alameda Urquijo, 48011 Bilbao, (Spain). Honorary Professor on Economics, University of Bath (UK).

4 BC3 and IKERBASQUE, Basque Foundation for Science. Alameda Urquijo, 48011 Bilbao, (Spain). Dept Land Economy, 19 Silver St., CB39EP, Cambridge (UK).
} 


\section{Introduction}

The discussion on discount rates is not new in the economic literature. Well-known economists such as Arrow (1963, 1965, 1996), Solow (1974), Sen (1967), Samuelson (1980), Lind (1982), Dasgupta, Maler and Barret (1999), Weitzman (2001) and Zeckhauser and Viscusi (2008) among many others have devoted great efforts to understanding how economists can reconcile the wellbeing of present and future generations. The debate on discounting is highly relevant in the context of climate change economics. Both the celebrated and contentiously argued Stern's report (Stern et al.., 2007), supported the use of rates close to zero on the grounds that future generations might well not exist and this has triggered the reaction of scholars such as Nordhaus (2007) who argues in favour of higher rates and has provided potent criticisms to the values provided by the Stern report, in part due to the low discount rates used in the calculations. Tol and Yohe $(2006,2009)$ have suggested that Stern might be right but for the wrong reasons and that the use of low rates if time horizon is extended can increase damages very substantially.

Generally, albeit the existing debate on discounting, there is some consensus by leading scholars supporting the case for rather low and also possibly declining discount rates when addressing the problem of climate change. As Weitzman (2007) pointed out "it is not an exaggeration to say that the biggest uncertainty of all in the economics of climate change is the uncertainty about which interest rate to use for discounting" The idea of using low social discount rates for natural resource management is not new and has been defended on various grounds and modelling exercises. Chichilnisky (1997) introduced two axioms for sustainable development, which, in combination, require that neither the present nor the future should play a dictatorial role in society's choices over time. The implications of her approach to discounting is that the future would be discounted in a conventional manner only in the "near future", but after a point- the socalled 'switching date'- remaining effects would not be discounted at all (i.e. a zero rate will prevail). Li and Löfgren (2000) considered the case of two identical individuals, hence with identical preferences except for their personal rate of time preference. In their model the overall societal objective is to maximize a weighted sum of utility for both individuals which results in a similar outcome to that of Weitzman's discounting approach, i.e, the individual with lower discount rate is given the dominant weight as time goes by and the collective discount rate declines over time. 
Further, Weitzman (2007 and 2008) has also argued that even negative discount rates are possible when assessing the costs of climate change due to the high expected costs to future generations (albeit at low probability). More recently he has also recommended that discount rates decline over time toward the lowest possible value (Gollier and Weitzman, 2010)5. As said above, currently the discounting debate is especially relevant in the context of climate change, given the expected high costs that future generations are likely to bear based on past and current economic activities. Summers and Zeckhauser (2008) based on psychological principles have suggested four dimensions for climate change policies and defend using positive but low discount rates. Interestingly, Dasgupta (2008) has also argued that discount rates should be set based not only on economic forecasts but also on society's conception of distributive justice "concerning the allocation of goods and services across personal identities, time and events" and points out that an optimum policy may well not exist. He also argues in favour of using rather low discount rates on the basis of the expected future income inequalities. Alternatively, Gollier (2008) has argued for a systematically declining discount rate justified on the basis of future shocks on economic growth going from ranges close to $4 \%$ for 100 years periods to $1-3.5 \%$ ranges for 1000 year periods. While this is an approach that is intuitively appealing the problem of time inconsistency is a thorny one since as Guo (2004) notes plans made at one point in time can be contradicted by later behaviour. Heal (1998) has shown that almost all types of declining discount rates result in time inconsistency.

The purpose of this paper is to make a practical proposal for determining the discount rate for projects or programmes in which one of the options is to maintain or improve land in its natural state. Making decisions about optimal investments in green infrastructure necessitates setting social discount rates. We illustrate this in the context of this special issue on valuation and management of marine ecosystems, for a case in the Basque Country where a contentious project to build a sea port involves reclaiming natural land that has ecological value for marine and terrestrial ecosystems.

\footnotetext{
${ }^{5}$ There is a problem with declining discount rates, namely the possibility of time inconsistency. 'Time inconsistency' refers to the situation where plans made at one point in time are contradicted by later behaviour. For example, as Guo (2004) notes, "if a government decides to use high discount rates for the near future but lower ones for the far future, the immediate large spending will be easily justified. However, when later governments review the policy, they may conclude that this earlier policy was not optimal and decide to increase the discount rate again, which will lead to higher consumption than planned."
} 
Economists working on such problems sooner or later have to deal with the difficult decision of choosing an appropriate discount rate and while some governments now offer quite precise advice, the issue is still controversial and does not have wide agreement ${ }^{6}$.

We recommend an ethically simple and intuitively approach that helps to choose a social discount rate when designing and evaluating land conservation options: the rule is based on the idea that any policy maker should try to value equivalently and consistently a track off land that is in its natural state and another one which has been designated as appropriate for development (namely with the permission to transform it to built up land, e.g., for residential use). This is based on the idea that the long term value of a naturally preserved land track is at least equivalent to the value of land with permission to built up, and improvements to the former should be evaluated using a discount rate that has been determined on the basis of this "equivalency principle”.

This assumption implies giving the same weight to both types of land, which in turn assumes that future generations would give the same importance (and the same economic value) to natural land and to the land for residential use, as a minimum. This statement has the advantage of avoiding making other uncertain assumptions about the expected welfare or growth rate of consumption of future generation (implied in the Ramsey rule), and the magnitude of the projected impacts in the case of climate change for example (which might turn to be wrong in future realities).

Section 2 makes the case for the calculation of appropriate discount rates for land-related assets taking into consideration local conditions and social preferences. Section 3 of the paper illustrates the proposed discounting rule with the information collected from several natural asset valuation studies. Section 4 applies the rule in a specific case for the Basque Country. Finally, section 5 offers some concluding remarks.

\footnotetext{
${ }^{6}$ The biggest attempt has been made by the UK Treasury in its Green Book 2003, where the recommended social discount rates are declining with time. The current recommendation is to use rates of $5 \%$ for periods of zero to 30 years, declining to $1 \%$ for periods of over 300 years. Similarly, France decided in 2004 to replace its constant discount rate of $8 \%$ to a $4 \%$ discount rate for maturities below 30 years, and a discount rate that decreases to $2 \%$ for larger maturities. There is not, however, an EU-wide recommendation, or one that applies to other developed and | developing countries.
} 


\section{Implications for discounting of the equivalency principle}

For heuristic purposes, let us assume the following situation that in time period zero $(\mathrm{t}=0)$ there are two tracks of land of identical size, e.g., one hectare, named $N$ and $U$, both with identical environmental and site-characteristic attributes such as location, slope, orientation, proximity to infrastructures, etc. In this case the value of $N$ and $U$ would be equal, and it could be represented by a price $\mathrm{P}_{\mathrm{N}}$ and $\mathrm{P}_{\mathrm{U}}$ if a land market exists, i.e, $P_{N}=P_{U}$. Now let us assume that in the future $(\mathrm{t}=1)$ an administrative procedure is granted so that track $\mathrm{U}$ now has the right to be built upon. $\mathrm{U}$ becomes a land with the potential to be developed while $\mathrm{N}$ stays natural. That is, $\mathrm{U}$ is granted the possibility to have industrial, commercial or residential construction. This will automatically increase the market price of $\mathrm{U}$ significantly (maybe 10 to 20 times higher). Thus, $P_{N}<P_{U}$.

This situation is relatively common in most countries where a "well informed" government decides to grant building rights to different pieces of land. When this occurs, decisions about either tract of land will be heavily influenced by the higher value attached to $\mathrm{U}$. Taking into account future generations opens the discussion on the discount rate that should be used for this purpose. If both tracks of land remain under the same use in the future, the value for future generations of both $\mathrm{N}$ and $\mathrm{U}$ would be equal. If instead they stay forever as in $\mathrm{t}=1$ the market interest rate will play a role for the calculation of the present value of $\mathrm{U}$. But it is not so clear which is the discount rate that should be applied to value $\mathrm{N}$ as the market is unlikely to internalize important environmental values.

While for $\mathrm{U}$ the market interest rate is normally used to discount future costs and benefits from any investment associated with it, for $\mathrm{N}$ the question is which discount rate should be used. What this paper proposes is a basic rule to calculate the discount rate that should be used when valuing natural assets. We argue that the discount rate to be used for $\mathrm{N}$ in any analysis is the one resulting from assuming the same present value for both $\mathrm{N}$ and $\mathrm{U}$. This is the equivalency principle. The value for $\mathrm{U}$ is $\mathrm{P}_{\mathrm{U}}$, i.e, the price per hectare observed in the market. For $\mathrm{N}$, which has environmental values not traded in the market, this value is usually calculated using nonmarket valuation methods and is represented by the present value $\mathrm{PV}_{\mathrm{N}}$ per hectare. The type of land which we refer to in our analysis is the undeveloped residential land. 
Using the conventional discounting formula for the present value:

$$
P V_{N}=\sum_{t=1}^{T} \frac{\left(V_{N}\right)_{t}}{\left(1+i_{N}^{B}\right)^{t}}=P_{U}
$$

Where $P V_{N}$ is the present value, i.e. the discounted value of the benefit in year $t, V_{N}$ is the benefit in year $t$, expressed in terms of annual value per hectare (flow) of $\mathrm{N}$, and $i_{N}$ is the discount rate for natural assets. However, lands generate benefits in perpetuity, so that the appropriate discounting formula for infinite time scale should be used (Mills et al., 1994):

$$
P V_{W}=\frac{V_{N}}{i_{N}^{8}}=P_{U}
$$

The equation assumes that the benefits are constant over time. However, flows can be expected to increase over time in real terms as a result of growing real incomes and an increasing scarcity of services from natural capital (Krutilla, 1967). Furthermore, educational improvement in the future might lead to a higher appreciation of the use of natural land (Barker, 2006). In this case, the present value for a finite time scale would be:

$$
P V_{N}=\sum_{t=1}^{T} \frac{V_{N}^{0}(1+g)^{t}}{\left(1+i_{N}\right)^{t}} \approx \sum_{t=1}^{T} \frac{V_{N}}{\left(1+i_{N}-g\right)^{t}}
$$

Where $g$ stands for the growth rate or appreciation of the benefits of the natural land over time. Consequently, equation (1) for a perpetuity becomes:

$P V_{N}=\frac{V_{N}}{\left(i_{N}^{*}-g\right)}=P_{U}$

The flow of benefits for $\mathrm{N}$ includes both use and non-use values taken from stated or revealed preference approaches. Use values are derived for example from the individual willingness to pay to visit the natural site (contingent valuation or choice experiments) or from the households' expenses actually supported for the visit (travel cost). Non-use values are expressed in terms of the willingness to pay to protect the natural asset and preserve its biodiversity level (existence value). 
The calculation of $i_{N}^{*}$, using the conventional discount formula (equation 1), relies on numerical or graphical methods, being based on the same conceptual framework of the IRR. $i^{*}{ }_{N}$ is the discount rate at which the present value of the natural assets equals the price of the land for residential use (with permission to build). If $\mathrm{t}=1$, equation (1) can be written as:

$P V_{N}=\sum_{0}^{1} \frac{\left(V_{N}\right)_{t}}{\left(1+i_{N}^{8}\right)^{1}}=V_{N}+\frac{V_{N}}{\left(1+i_{N}^{*}\right)^{1}}=P_{U}$

and solving for $i_{\mathbb{N}}$ :

$\frac{2 V_{N}-P_{U}}{P_{U}-V_{N}}=i_{N}^{8}$

For any number of time periods $\mathrm{t}$, the sequence of discounted flow values of $\mathrm{N}$ is a polynomial function with n degree, so that finding $i^{*}$ that equates $P_{U}$ and $P V_{N}$ requires us to find the roots of the polynomial. Different methods can be used for this purpose, such as the linear interpolation using trials and error methods or the Newton-Raphson method. The first allows is simpler but allows only an approximation of the discount rate, while the second uses algorithms to find successively improved approximations to the roots of the function (Tjalling and Ypma, 1995).

For simplicity using the formula of the perpetuity (Eq. 4):

$$
i_{N}^{*}=\frac{V_{N}}{P_{U}}+g
$$

\section{Illustrating the equivalency rule to existing valuation studies}

In order to illustrate the application of the equivalency rule we have identified a number of case studies from peer reviewed published papers, conducted in different regions, excluding those from developing countries, and that contain explicit and detailed information about annual nonmarket values per hectare (TEV) for different types of habitats.

The TEV is taken as an annual flow value for a specific point in time. In some cases, expectations of changes in this value over time are given. Since due to economic growth or 
associated scarcity of the selected habitats people in the future might be willing to pay more for the benefits of preserving those habitats, an exogenous growth rate of the TEV associated with the growth rate of real per capita income has been introduced. Hence we apply the equivalency rule to calculate the implicit discount rate that ought to be applied to the management of natural habitats under two assumptions: (a) that future flow values are equal to the present ones and (b) future flow values grow at the rate of expected growth or real per capita incomes (for this we have used the A2 and B2 IPPC scenarios). For simplicity we have not included the effect of the income elasticity of the WTP.

For each case study we have estimated the discount rate $i *{ }_{N}$ that would result from the application of the suggested rule, using equation 5 (for the perpetuity case). As regards the price of the land for residential use, this should be equal to the average price observed in the market for the residential land located in the vicinity of the case study site. In the first two case studies, located in the Basque Country (North of Spain), we used the average price of residential land for the coastal Basque province of Gipuzkoa (where the two studies are located), excluding the cities, equal to 5.4 million $€_{2000}$ (Basque Government, 2004). In the other case studies, we used as a first attempt the average price of residential land estimated at national level. For United Kingdom we refer to Property Market Report 2006 (Valuation Office Agency), while for the countries located in the United States we refer to Morris and Heathcote (2007) providing prices of residential land for 50 US states and the District of Columbia ${ }^{7}$. The estimated discount rate for each case study is reported in Table 1 here below.

\section{[TABLE 1]}

The estimated discount rate depends on the magnitude of the original annual non-market value per hectare, on the average price per hectare of the land for residential use in the vicinity and on the expected growth rate of per capita income. In the reported case studies, the discount rate is generally very small. When using constant flows, the estimated discount rate is lower compared to the two alternative scenarios which take into account an increase in the real GDP. It should be noted, however, that in some cases the WTP for habitat conservation might be quite high,

\footnotetext{
${ }^{7}$ A further refinement of the study should look at the specific price of residential land located as close as possible to the study site. If more sites are under analysis, located in a broader geographical area, then the average price of residential land for that area should be use.
} 
especially when such habitat is rare. Under the equivalency rule high discount rates, e.g., above four percent (an often cited threshold for the social rate of discount, see e.g., Gollier, 2010, may result. This supposes a paradox as any future investment for the conservation of such sites would be heavily discounted in the future. We suggest that is such cases valuation as a way to inform policy may give way to the precautionary principle instead, whereby monetary valuation does not play a fundamental role in policy decision making.

The Total Economic Value per hectare reported from stated or revealed preferences depend on many factors, such as the site physical characteristics (biome, habitat), the socio-economic variables (income per capita, population, etc), the relative importance of the different types of benefits (use and non-use), as well as the valuation method used. All these variables are influencing the values per hectare which are very site-specific. The appropriate non-market value to be used for a natural site should therefore be selected taking into account the context-specific variables identifying the territory (site and socio-economic characteristics). This requires a specific knowledge of the territory at a local level. The proposed method to identify the discount rate for natural assets is therefore based on the individual preferences which in turn depend on the site characteristics and the socio-demographic features of the area.

We suggest the following steps to estimate the appropriate discount rate. First, we have to select the most suitable case study which should be representative of the territory under analysis (in terms of habitats). The selection should take into account only TEVs or good approximation of TEV. Second, we need to identify the average price of residential land in the same territory, which should be the closest as possible to the case study site. Third, we need to make an assumption of the rate of growth of future flows of services from the land. Based on these we calculate the discount rate at which the present value of the natural site equals the average price of the land for residential use. This discount rate can be used then in all the choices concerning programmes or polices that relate to the use of the land in the territory where the case study is located. 


\section{An illustration from the Basque Coast}

The construction of a new seaport in Pasaia (Gipuzkoa) is attracting a lot of attention lately as it is projected in a cliff with significant environmental attributes named Jaizkibel. This is a zone that was incorporated in Natura 2000 network in 2004 and comprises 2400 ha of natural land with 15 zones declared of high ecological interest. The project is currently been evaluated by the Ministry of the Environment, Rural Affairs and Marine Issues of the Spanish Government within the Environmental Impact Assessment (EIA) procedure. The total investment (of mainly public resources) needed to go ahead with the project ranges from $€ 750$ million to $€ 1.2$ billion depending on the alternative chosen. The information for this case study has been obtained from the Environmental Sustainability Report (Informe de Sostenibilidad Ambiental, ISA 2010) that has been submitted for the EIA procedure by the Pasaia Port Authority. These documents are available at the official site of the Port Authority. Two other research papers have also been used for this case-study, Hoyos et al (2008) and Hoyos et al (2009).

The high environmental value of the Jaizkibel area is very well summarised in Hoyos et al (2009), who define the landscape as: “[...] highly valuable because the mountain runs along the coast with an abrupt fall at the western end, with cliffs up to 240mhigh. In these cliffs, which are geologically highly valued because of the layout of the sandy strata, lives the Armeria euskadiensis, an endemic plant of the Basque coast catalogued as being in danger of extinction. At the eastern end, the terrain is not so abrupt and there are small beaches and gullies formed by the courses of streams flowing into the Bay of Biscay. In these areas, interesting species of flora can be found such as tropical ferns (Woodwardia radicans and Trichomanes speciosum), which are extremely rare in the rest of Europe. The rest of Mount Jaizkibel comprises a non-wooded forest area with some scrubland and pasture land associated with local 'baserris' (family-run farms). Nevertheless, some areas maintain their original tree cover with groves of Quercus robur and Quercus pyrenaica oaks. Colonies of lesser black-backed gulls and yellow-legged gulls (Larus fuscus and Larus cachinnans) nest on the cliffs. Other interesting birds such as the European storm petrel (Hydrobates pelagicus), the green cormorant (Phalacrocorax aristotelis) and the peregrine falcon (Falco peregrinus) can also be found in this natural area. On the mainland, there are numerous species of amphibians, reptiles and mammals including the palmate newt (Triturus helveticus), the midwife toad (Alytes obstetricans), the dark-green whip 
snake (Coluber viridiflavus) and the greater horseshoe bat (Rhinolophus ferrumequinun). The seabed harbours different types of molluscs, sea urchins and crustaceans, as well as some species of fish and dolphins. The seabed in the area is also home to various types of green, red and brown seaweed, and one of the most important patches of red seaweed on the Basque coast. In short, Jaizkibel's most outstanding environmental attributes are its landscape, its autochthonous fauna and flora and its seabed life".

Hoyos et al (2008) estimated, using a choice modelling exercise, the economic value of preserving the Jaizkibel natural area in similar condition as it is today. The study determines that it will directly depend on the environmental damage that the construction of the projected seaport will generate. The higher the expected damage the greater the willingness to pay to preserve the area. With this purpose the paper defines three scenarios of potential damage (high, medium and low). The results show that the social welfare loss per year for a low damage scenario was estimated in $€ 172,110,000$, while a medium damage scenario will provoke a loss of $€ 344,220,000$ and a high damages one a loss of $€ 535,520,000$. This is the information that will be used in this case study as the environmental (social) cost of the project.

On the other side, information on the total economic impact of building the recommended alternative for the port (namely alternative $4^{8}$ ) is available from the ISA (2010). The report states that building the port will generate a positive net impact of $€ 542,686,980$ annually for the period 2010-2054 ${ }^{9}$. The figure has been estimated applying an input-output Leontieff model, and fall within the ranges of a similar study carried out by the Bilbao Port Authority ${ }^{10}$.

With these pieces of information one can derive a very simple Cost-Benefit Analysis (CBA) to illustrate the methodology proposed in this paper showing how the election of the discount rates proves to be essential for an evaluation exercise such as this one.

If the public authorities need to make a decision whether to build the port or not, one could expect that the expected economic benefits of the project (in this case the total economic impact) could be compared to environmental cost. To illustrate our point we assume that the authority decides to discount the economic benefits at a market rate (let us assume it is $11 \%$ ) to calculate

\footnotetext{
${ }^{8}$ The other alternatives are 3,2,1 and 0 which represents not building the port at all.

${ }^{9}$ This value is net of the investment cost needed to build the port and the infrastructures.

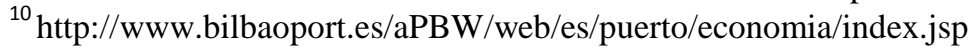


the present value of expected benefits for the period 2010-2054 and uses the same rate for the welfare losses. The resulting values are given in the first line of table 2 below. For the three scenarios of the environmental cost the present value of the benefits ( $€ 5.4$ bill) is higher than the present value of the expected environmental cost ( $€ 1.7$ billion, $€ 3.4$ billion and $€ 5.3$ billion) and consequently, building the port would be justified. The total impact of the project (i.e. economic cost minus environmental cost) will be $€ 3.7$ bill, $€ 1.9$ bill and $€ 71$ mill for the three scenarios (see table 3).

\section{[TABLE 2]}

However, if a well informed policy maker decides to use different discount rates to calculate the present value of the benefits from the one that would use to obtain the present value costs the story changes. Let us assume that following the ranges suggested by Gollier (2008) a $4 \%$ rate is used for environmental costs while $11 \%$ is used for the economic benefits. Then the CBA shows that only under the scenario of low impact would it be justified to opt for the construction of the port. This indeed makes a big difference the result of the analysis and therefore on the viability of the project.

\section{[TABLE 3]}

Let us move now one step further to illustrate the case of choosing the discount rates resulting from the method suggested in the paper. In this case, the estimated discount rate for low impact scenario (that is the one resulting from the rule of thumb) would be $1.31 \%$ (Table 2, using constant flows). Consequently the total impact will change dramatically to a loss of $€ 473$ mill. The other two scenarios require using a $2.6 \%$ and a close to $4 \%$ rates and will also generate a negative result.

The numbers showed here easily illustrate the case, choosing a wrong discount rate makes that the traditional CBA are totally biased, suggesting that a project should be promoted when a closer look at the values of nature assets strongly suggest not to undertake it. These numbers are real numbers from a future project that it is been discussed at policy arena for the past few years. Deciding to go ahead with this project is pending on an administrative procedure. Short sighted policy makers could decide to go ahead with a $€ 750$ million investment while a more sustainable approach clearly shows that the port should not be constructed. 


\section{Concluding remarks}

Identifying the appropriate social discount rate is crucial for policy action especially in the context of long-term environmental impacts. Two critical arguments should be taken into account in the discussion about the choice of the discount rate in intergenerational choices about the environment. The estimation of the discount rate in the welfare approach is based on the fact that future generation will be richer than ours, according to which "one should not be ready to pay one euro to reduce the loss borne by future generations by one euro, given that these future generations will be so much wealthier than us" (as mentioned by Gollier, 2008). However, in the current situation of uncertainty, we cannot say with certainty that global GDP is expected to continue to rise over time. In this context, the definition of the discount rate cannot be based on expectations about future economic growth alone. Second, according to the decreasing marginal utility theory, if a resource becomes scarcer, its value is expected to raise compared to the less scarce resources. Some natural ecosystems (such as wetlands, mangroves, coral reefs) can become very rare in the future, and this would increase their value and the price of the corresponding land. In the most extreme case that human life would be threatened due to the disappearance of critical natural ecosystems, the value of these ecosystems might see a dramatic escalation, to the point of reaching some critical threshold where the notion of economic value itself would become meaningless. In a situation of higher scarcity of natural resources in the future, if the governments would be willing to invest in these resources for protecting their natural ecosystem, they will have to pay a much higher price. So we can reasonably think that low social discount rates (giving today high present values) could be reflected in higher actual prices of natural lands in the future.

What we propose in this paper simplifies the discussion about which discount rate should be used by policy makers under the current level of uncertainty characterising climate change impacts and long-term risks to future generations. While the current "main intellectual battleground is whether we should be using discount rates in the range of $3 \%$ or discounting by only a token nonzero amount, such as $0.1 \%$, as mentioned by Zeckhauser and Viscusi (2008), the results reported in this paper show that the discount rate resulting from the application of the equivalency rule ought to vary according to the annual estimated benefits of the natural land (WTP), the market price assigned to residential land and to the expected increase of the benefits 
of the land over time. Based on this rule we suggest, that the estimated discount rates ought to be quite low hence supporting policy decisions that are more oriented towards the protection of the environment than they actually are. 


\section{References}

Autoridad Portuaria de Pasaia, (2010), "Informe de Sostenibilidad Ambiental del Plan Director de Infraestrcuturas del Puerto de Pasaia”. Available at

http://www.puertopasajes.net/en/index.php?lang=en

Arrow, K. J. (1965). Aspects of the theory of risk-bearing. Helsinki: Yrjö Jahnssonin säätiö.

Arrow, K. J. (1963). Social choice and individual values (2nd ed.). New York: Wiley (1951).

Arrow, K. J. (1999). Discounting, morality, and gaming. In P. R. Portney, \& J. P. Weyant (Eds.), Discounting and intergenerational equity. Washington, DC: Resources for the Future.

Arrow, K. J., et al. (1996). Intertemporal equity, discounting, and economic efficiency. In J. P. Bruce, H. Lee, \& E. F. Haites (Eds.), Climate Change 1995: Economic and social dimensions of climate change, contribution of working group III to the second assessment report of the intergovernmental panel on climate change. Cambridge: Cambridge University Press.

Cobbing P. and Slee B. (1994). "The application of CVM to a land use controversy in the Scottish Highlands". Landscape Research 19(1), pp. 14-17.

Costanza, R., R. d'Arge, R. de Groot, S. Farber, M. Grasso, B. Hannon, K. Limburg, S. Naeem, R. O'Neill, J. Paruelo, R. Raskin, P. Sutton, and M. van den Belt. (1997). "The value of the world's ecosystem services and natural capital”. Nature 387:253-269.

Dasgupta, P., Maler, K. G., \& Barrett, S. (1999). Intergenerational equity, social discount rates, and global warming. In P. R. Portney, \& J. P. Weyant (Eds.), Discounting and intergenerational equity. Washington, DC: Resources for the Future.

Gollier C. And Weitzman, M. L. (2010), "How should the distant future be discounted when discount rates are uncertain?. Economic Letters 107, 350-353.

Groom, B., Hepburn, C., Koundouri, P. and Pearce, D. (2005), "Declining Discount Rates: The Long and the Short of it”. Environmental \& Resource Economics (2005) 32: 445-493. 
Hanley, N. and Spash, C.L. (1993), The protection of ancient woodlands, Cost-benefit Analysis and the Environment. Nick Hanley, Clive L Spash, Edward Elgar. pp. 219-227.

Hanley, N. and S. Craig (1991), The Economic Value of Wilderness Areas: An Application to the Krutilla-Fisher Model to Scotland's 'Flow Country', Environmental Policy and the Economy, edited by Frank Dietz, Frederick van der Ploeg, and Jan van der Straaten. Amsterdam: Elsevier Science Publishers B.V.

Hoyos, D., Mariel, P. and Fernández-Macho, J. (2009), “The influence of cultural identity on the WTP to protect natural resources: Some empirical evidence”. Ecological Economics 68 (2009) 2372-2381.

Hoyos, D., Riera, P., Fernandez-Macho, J., Gallastegui, C. and Garcia, D., (2008), "Valuing Environmental Impacts of Coastal Development Projects: A Choice Modelling Application in Spain”. Report to the Department of Environment of the Basque Government.

Jacobs., (2004). An economic assessment of the costs and benefits of Natura 2000 sites in Scotland. Final Report. Scottish Executive 2004. Environment Group Research Report 2004/05.

Kramer RA, Holmes TP, Haefele M. (2003). Using contingent valuation to estimate the value of forest ecosystem protection. In: Ills EO, Abt KL (eds) Forests in a Market Economy. Kluwer, Dordrecht.

Lind, R. C. (Ed.) (1982). In Discounting for time and risk in energy planning. Baltimore: Johns Hopkins University Press.

Morris, A. D. and Heathcote, J. (2007), "The Price and Quantity of Residential Land in the United States". Journal of Monetary Economics, vol. 54 (8), p. 2595-2620; data located at Land and Property Values in the U.S., Lincoln Institute of Land Policy http://www.lincolninst.edu/resources/

Nordhaus, W. D. (2007). The Stern Review on the economics of climate change. Journal of Economic Literature, 45(3), 686-702.

Ostrom, Elinor (1990). Governing the Commons: The Evolution of Institutions for Collec-tive Action. New York: Cambridge University Press. 
Pearce, D. W. (2003), "The social cost of carbon and its policy implications". Oxford review of Economic Policy 19(3), 1-32.Phillips S. and Silverman, R. (2008), "Greater than zero: toward the total economic value of Alaska's National Forest Wildlands". The Wilderness Society, Washington, DC.

Scarpa, R., Hutchinson, W.G., Chilton, S.M., Buongiorno, J. (2000). "Importance of forest attributes in willingness to pay for recreation: a contingent valuation study of Irish forests". For Policy Econ 1:315-329.

Sen, A. K. (1967). "Isolation, Assurance, and the Social Rate of Discount", Quarterly Journal of Economics 81: 172-224.

Shechter, M., Reiser, B. and Zaitsev, N. (1998). "Measuring passive use value: pledges, donations and CV responses in connection with an important natural resource". Environ Resour Econ 12:457-478.

Solow, R. M. (1974). Intergenerational equity and exhaustible resources. Review of Economic Studies, 41 (Symposium Issue), 29-45.

Stern, N. H., et al. (2007). The economics of climate change: The Stern Review. Cambridge: Cambridge University Press.

Tol y Yohe (2006): »A Review of the Stern Review» World Economics 7(4): 233-50.

Weitzman, M. L. (2001). Gamma discounting. American Economic Review, 91(1), 260-271.

Weitzman, M. L. (2007). The Stern Review of the economics of climate change. Journal of Economic Literature, 45(3), 703-724.

Woodward, R.T. and Wui, Y.S., (2001), "The economic value of wetland services: a metaanalysis”. Ecological Economics, 37, pp 257-270. 
Table 1. Estimated discount rates for different case studies based on the equivalency principle.

\begin{tabular}{|c|c|c|c|c|c|c|c|}
\hline Study & Location & Habitat & $\begin{array}{l}\text { Price per ha } \\
\text { land for } \\
\text { residential } \\
\text { use }(€ 2000)\end{array}$ & $\begin{array}{l}\text { Value per ha per } \\
\text { year } \\
\text { (standardized } \\
€ 2000 \text { ) }\end{array}$ & $\begin{array}{l}\text { Estimated } \\
i{ }_{N}(\%) \\
\text { Constant } \\
\text { flows }\end{array}$ & $\begin{array}{l}\text { Estimated } \\
i{ }_{N}(\%) \\
\text { Increasing } \\
\text { flows } \\
(\text { IPCC A2) }\end{array}$ & $\begin{array}{l}\text { Estimated } \\
i{ }_{N}(\%) \\
\text { Increasing } \\
\text { flows } \\
(\text { IPCC B2) }\end{array}$ \\
\hline $\begin{array}{l}\text { Prestige } \\
\text { Report } \\
\text { (Galarrage } \\
\text { et. al, 2004) }\end{array}$ & $\begin{array}{l}\text { Basque } \\
\text { Country } \\
\text { (coastal } \\
\text { provice of, } \\
\text { Gipuzkoa) }\end{array}$ & $\begin{array}{l}\text { Sandy and shingle } \\
\text { beaches }\end{array}$ & $5,418,912$ & 8,415 & 1.55 & 3.03 & 2.61 \\
\hline \multirow[t]{3}{*}{$\begin{array}{l}\text { Hoyos et al. } \\
(2007)\end{array}$} & $\begin{array}{l}\text { Basque } \\
\text { Country } \\
\text { (coastal } \\
\text { provice of, } \\
\text { Gipuzkoa) }\end{array}$ & $\begin{array}{l}\text { Jaizibel Mountain } \\
\text { (Natura 2000) : cliffs } \\
\text { sandy strata, } \\
\text { beaches/gullies, non- } \\
\text { wooded forest area, } \\
\text { crubland/pasture }\end{array}$ & $5,418,912$ & $\begin{array}{l}70,518 \\
\text { (lower bound WTP) }\end{array}$ & 1.3 & 2.79 & 2.35 \\
\hline & & & & $\begin{array}{l}141,034 \\
\text { (medium bound } \\
\text { WTP) }\end{array}$ & 2.6 & 4.09 & 3.65 \\
\hline & & & & $\begin{array}{l}219,417 \\
\text { (upper bound WTP) }\end{array}$ & 3.97 & 5.53 & 5.1 \\
\hline $\begin{array}{l}\text { Hanley and } \\
\text { Spash } \\
(1993)\end{array}$ & $\begin{array}{l}\text { United } \\
\text { Kingdom }\end{array}$ & $\begin{array}{l}\text { Forest ancient wood } \\
\text { (small with few } \\
\text { substitutes) }\end{array}$ & $3,716,471$ & 9,567 & 0.25 & 1.75 & 1.3 \\
\hline
\end{tabular}




\begin{tabular}{|c|c|c|c|c|c|c|c|}
\hline $\begin{array}{l}\text { Cobbing } \\
\text { and Slee } \\
(1994)\end{array}$ & Scotland & $\begin{array}{l}\text { Mar Lodge Estate, } \\
\text { Scottish Highlands }\end{array}$ & $3,716,471$ & 1,629 & 0.044 & 1.53 & 1.095 \\
\hline $\begin{array}{l}\text { Jacobs } \\
(2004)\end{array}$ & Scotland & $\begin{array}{l}7 \text { NK2 sites (Natura } \\
2000 \text { ) }\end{array}$ & $3,716,471$ & 401 & 0.0107 & 1.497 & 1.0618 \\
\hline $\begin{array}{l}\text { Hanley and } \\
\text { Craig } \\
(1991)\end{array}$ & $\begin{array}{l}\text { Northern } \\
\text { Ireland }\end{array}$ & Forested area & $3,716,471$ & 175 & 0.0047 & 1.4903 & 1.0556 \\
\hline $\begin{array}{l}\text { Costanza } \\
(1997)\end{array}$ & USA & Mangroves & 437,263 & 5,376 & 1.23 & 2.72 & 2.28 \\
\hline $\begin{array}{l}\text { Woodward } \\
\text { and Wui } \\
(2001)\end{array}$ & USA & Wetlands & 437,263 & 9,496 & 2.17 & 3.65 & 3.22 \\
\hline $\begin{array}{l}\text { Phillips and } \\
\text { Silverman } \\
(2007)\end{array}$ & Alaska & $\begin{array}{l}\text { Primary, old-growth } \\
\text { temperate rainforest }\end{array}$ & 560,678 & 323 & 0.058 & 1.54 & 1.109 \\
\hline
\end{tabular}


Table 2: Present values of impacts derived from constructing the port

Discount rates

applied to $\quad$ Economic benefit $€(\mathbf{2 0 1 0 - 2 0 5 4 )}$

benefits

$11 \% \quad 5,426,207,784$

Environmental cost $€(\mathbf{2 0 1 0 - 2 0 5 4 )}$

\begin{tabular}{llll}
\hline $\begin{array}{l}\text { Discount rates } \\
\text { applied to } \\
\text { costs }\end{array}$ & LOW & MEDIUM & HIGH \\
\hline $11 \%$ & $1,720,890,045$ & $3,441,780,091$ & $5,354,546,727$ \\
$4 \%$ & $3,708,771,075$ & $7,417,542,150$ & $11,539,835,489$ \\
$1.31 \%$ & $5,900,026,689$ & n.a & n.a \\
$2.60 \%$ & n.a & $9,304,090,225$ & n.a \\
$3.97 \%$ & n.a & n.a & $11,592,309,720$ \\
\hline
\end{tabular}

Table 3: Total impact of constructing the port, a basic CBA approach

TOTAL IMPACT (economic \& environmental)

\begin{tabular}{lccc}
\hline Discount rate for costs & Low & Medium & High \\
$11 \%$ & $3,705,317,738$ & $1,984,427,693$ & $71,661,057$ \\
$4 \%$ & $1,717,436,709$ & $-1,991,334,366$ & $-6,113,627,705$ \\
$1.31 \%$ & $-473,818,905$ & n.a & n.a \\
$2.60 \%$ & n.a & $-3,877,882,441$ & n.a \\
$3.97 \%$ & n.a & n.a & $-6,166,101,936$ \\
\hline
\end{tabular}




\title{
BC3 WORKING PAPER SERIES
}

\author{
Basque Centre for Climate Change (BC3), Bilbao, Spain
}

The BC3 Working Paper Series is available on the internet at the following addresses:

http://www.bc3research.org/lits_publications.html

http://ideas.repec.org/s/bcc/wpaper.html

BC3 Working Papers available:

2010-14 Kaysara Khatun: Competing Ecosystem services: an Assessment of Carbon and Timber in the Tropical forests of Central America

$2010-15$

Karen Pittel and Dirk Rübbelke: Local and Global Externalities, Environmental Policies and Growth

2010-16

Margherita Grasso, Matteo Manera, Aline Chiabai, and Anil Markandya: The Health Effects of Climate Change: A Survey of Recent Quantitative Research

2010-17

Luis Mari Abadie, Ramon Arigoni Ortiz and Ibon Galarraga: The Determinants of Energy Efficiency Investments in the U.S.

2011-01

Roger Fouquet: Long Run Trends in Energy-Related External Costs

2011-02

2011-03

2011-04

Dirk Rübbelke: International Support of Climate Change Policies in Developing Countries: Strategic, Moral and Fairness Aspects

Melanie Heugues: Endogenous Timing in Pollution Control: Stackelberg versus Cournot-Nash Equilibria

Karen Pittel and Dirk Rübbelke: International Climate Finance and its Influence on Fairness and Policy

2011-05 Wan-Jung Chou, Andrea Bigano, Alistair Hunt, Stephane La Branche, Anil Markandya, Roberta Pierfederici: Households' WTP for the Reliability of Gas Supply

2011-06 Roger Fouquet and Peter J.G. Pearson: The Long Run Demand for Lighting: Elasticities and Rebound Effects in Different Phases of Economic Development

Ibon Galarraga, David Heres Del Valle and Mikel González-Eguino: Price Premium for High-Efficiency Refrigerators and Calculation of Price-Elasticities for Close-Substitutes: Combining Hedonic Pricing and Demand Systems

Anil Markandya, Mikel González-Eguino, Patrick Criqui, Silvana Mima: Low Climate Stabilisation under Diverse Growth and Convergence Scenarios

2011-09

Martin Altemeyer-Bartscher, Anil Markandya and Dirk Rübbelke: The Private Provision of International Impure Public Goods: the Case of Climate Policy

2011-10

Aline Chiabai, Ibon Galarraga, Anil Markandya and Unai Pascual: The Equivalency Principle for Discounting the Value of Natural Assets: An Application to an Investment Project in the Basque Coast 